\title{
Loss of Renal Function Causes Premature Aging of the Immune System
}

\author{
Michiel G.H. Betjes Ruud W.J. Meijers Nicolle H.R. Litjens \\ Division of Nephrology and Transplantation, Department of Internal Medicine, Erasmus Medical Center, \\ Rotterdam, The Netherlands
}

\section{Key Words}

Aging - End-stage renal disease $\cdot$ Hematopoietic stem cells . Immune system · Inflammation · Oxidative stress · Thymus · Uremia

\begin{abstract}
Background: Uremia-associated immune deficiency is a well-known complication of loss of renal function and contributes significantly to the overall mortality and morbidity of patients with end-stage renal disease. Chronic inflammation and increased oxidative stress are underlying the uremiaassociated immune deficiency. Summary: In this review, the differential impact of uremia on the cellular immune system is summarized. Virtually all immune cells studied show a combination of an activated status and loss of function. However, uremia preferentially decreases the number and function of lymphoid cells while myeloid cells show normal and/or elevated cell numbers with increased production of inflammatory cytokines and reactive oxygen species. These particular changes are compatible with immunological aging, which is characterized by loss of thymic function, attrition of telomeres and an expanded memory $T$ cell population. Similar to aging in healthy individuals, the proinflammatory and potential cardiotoxic subsets of $\mathrm{CD} 28^{\text {null }} \mathrm{T}$ cells and $\mathrm{CD} 16^{+}$monocytes are increased. Epigenetically changed hematopoietic stem cells may be involved in immunological aging as specific DNA regions become hypermethylated. Proinflammatory $T$ cells and monocytes persist after kidney transplantation, which constitutes a persistent cardiovascular risk factor.
\end{abstract}

Possible therapeutic options to reverse or halt uremia-associated immunological aging are discussed. Key Messages: Premature aging of the immune system is a dominant feature in patients with end-stage renal failure, which corresponds to immunological aging in elderly healthy individuals, which is characterized by preferential loss of cells belonging to the lymphoid cell lineage, inflammation and expansion of proinflammatory immune cells.

c) 2013 S. Karger AG, Basel

\section{Introduction}

Progressive loss of renal function is associated with an impaired cellular immune system, which is known as uremia-associated immune deficiency. The clinical implications of this acquired immune deficiency on the patient with end-stage renal disease (ESRD), both in terms of morbidity and mortality, are substantial. For instance, ESRD patients are highly susceptible to infections, respond poorly to standard vaccination procedures and have an increased risk of cancer, especially virus-associated cancers $[1,2]$.

The proinflammatory milieu in ESRD patients is characterized by the presence of increased oxidative stress and activation of immune cells, which are highly interrelated phenomena [3]. It is assumed that retention of uremic molecules and cytokines are key mechanisms underlying the generation of oxidative stress and inflammation [3]. Recently, it has been shown that a 'leaky' gut in uremia

\section{KARGER}

E-Mail karger@karger.com

www.karger.com/bpu (c) 2013 S. Karger AG, Basel

0253-5068/13/0364-0173\$38.00/0 
may contribute significantly to the low-grade systemic inflammation [4]. Periodontitis, which is common in patients with chronic kidney disease, may further fuel inflammation and atherosclerotic complications [5].

The immune system is divided into an innate and adaptive part, but these systems are closely integrated. Expression of molecular pattern recognition receptors is pivotal in this respect as they allow for activation of a variety of both immune and nonimmune cells, thereby linking the tissue cell response to damage or invading pathogens to the innate and adaptive immune response. This is relevant to the uremia-associated proinflammatory response as the products of increased oxidative stress, such as advanced glycation end products or oxidized low-density lipoprotein, may activate cells via this family of receptors [6].

In recent years, it has become evident that a chronic inflammatory milieu may affect the cellular immune system by a previously unrecognized mechanism of immunological aging [7]. This offers a novel explanation for the uremia-associated immune defect. In addition, the chronic inflammatory milieu favors the expansion of proinflammatory cardiotoxic subpopulations of $\mathrm{T}$ cells and monocytes in ESRD patients.

In this review, these particular changes in the immune system are highlighted and the concept of immunological aging is discussed.

\section{Composition of the Immune System and Effects of Uremia}

\section{Innate Cellular Immune System}

This ontogenetically old defense system offers a direct and nonspecific response to infection and tissue injury. The key cellular elements are granulocytes, monocytes, dendritic cells (DC) and natural killer (NK) cells [8]. However, almost every nonimmune tissue cell may act in an orchestrated immune response. Peritoneal mesothelial cells, for example, produce several chemokines necessary for the intra-abdominal invasion of granulocytes after direct stimulation by bacteria or indirect stimulation by macrophage-derived cytokines $[9,10]$.

Polymorphonuclear Neutrophils. Polymorphonuclear neutrophils (PMN) are short-lived cells and particularly important in the defense against invading bacteria. The number of circulating PMN progressively increases as renal function declines, with signs of an increased basal activation state (neutrophil priming) but less phagocytosis and bacterial killing when tested in uremic serum [8].
These primed PMN may increase oxidative stress and add to the proinflammatory state of uremic patients [11]. Overall, PMN in ESRD patients show a combination of activation with decreased cell function [8].

Monocytes and Macrophages. Monocytes obtained from uremic patients have an activated profile with increased integrin and toll-like receptor expression and a higher secretion of proinflammatory cytokines under basal and activated conditions [8]. However, similar to granulocytes, the phagocytosis capacity may be decreased. Several monocyte subsets exist, which have recently been formally divided into subtypes using the differential expression of the lipopolysaccharide receptor CD14 and immunoglobulin receptor CD16. Typically, ESRD patients have an increased number of circulating proinflammatory monocytes $\left(\mathrm{CD} 14^{+} \mathrm{CD} 16^{+}\right)$and these inflammatory monocytes are associated with an increased risk for atherosclerosis and may contribute to vascular calcification in ESRD patients $[8,12]$. Impaired macrophage function may be involved in the delayed clearance of bacteria and induce inflammatory signals within the peritoneal cavity [9].

NK Cells. NK cells are lymphocytes identified by the expression of CD56 and CD16 cell surface receptors in the absence of the CD3 T cell receptor (TcR) complex. NK cells are important for the elimination of virus-infected cells and tumor cells, and potentiate DC function. The absolute number of NK cells is substantially decreased in ESRD patients and correlates with a decrease in glomerular filtration rate $[13,14]$. The lowered number of NK cells may contribute to decreased tumor immune surveillance, increased susceptibility to viral infections and less potent adaptive immune responses.

Dendritic Cells. DC are considered the most potent professional antigen-presenting cells in the immune system and effectively drive antigen-specific $\mathrm{T}$ cell responses. Different sources of DC are recognized: Langerhans cells within the skin, monocytes differentiating to DC and immature DC within the circulation. The latter population is divided in myeloid DC (mDC) and plasmacytoid $\mathrm{DC}(\mathrm{pDC})$. Uremia has a negative influence on the size and function of all known populations of DC although to a different extend [1]. In predialysis ESRD patients, $\mathrm{pDC}$ are decreased in relation to the loss of glomerular filtration rate, while $\mathrm{mDC}$ remain relatively unaffected $[1,15-$ 17].

\section{Adaptive Immune System}

The adaptive immune system deals with threats to the host in a highly specific way and has a memory function, 
which may persist for decades. Adaptive immune cells are $\mathrm{B}$ (B cells) and T lymphocytes (T cells). Adequate antigenic stimulation of lymphocytes requires signaling via the antigen receptor in combination with costimulatory molecules and proinflammatory 'danger' signals.

$T$ Cells. T cells are probably the best-studied immune cells in ESRD patients and typical findings include $\mathrm{T}$ cell lymphopenia, which is predominantly caused by severe loss of naïve $\mathrm{T}$ cells $[7,18]$. The cells have a phenotypically activated, proapoptotic profile but proliferation after polyclonal stimulation is poor if performed in uremic serum [7]. The increase in virus-associated cancers, tuberculosis and decreased vaccination responses to T-celldependent antigens in ESRD patients suggest a major clinical role for the impairment in T cell function [19]. A subset of CD4 $\mathrm{T}$ cells that downregulates immune responses, called regulatory $\mathrm{T}$ cells, also has a diminished function [8].

$B$ Cells. Similar to T cells, the circulating B cell population is decreased in ESRD patients, particularly naïve $B$ cells. B cells are also prone to apoptosis [20]. Their differentiation into immunoglobulin-secreting plasma cells after antigenic stimulation is not studied in ESRD patients.

\section{Concept of Premature Immunological Aging in ESRD Patients}

Physiological aging of the immune system is accompanied by a number of distinct changes, which may be signs of low grade chronic inflammation of unknown cause (hence the term 'inflamm-aging') [21]. As summarized in table 1, age-related changes in immune cell numbers and function show a striking resemblance with features of ESRD immune deficiency. Immunological aging is most evident and best studied for the lymphoid adaptive immune system, in particular the T cells. Progenitor T cells are generated in the bone marrow from hematopoietic stem cells (HSC) and populate the thymus. From the thymus, newly formed $\mathrm{T}$ cells with a rearranged $\mathrm{TcR}$ are released into the circulation and migrate through lymphoid tissue. A circular nonreplicating DNA fragment remains as a remnant of the rearranged $\mathrm{TcR}$ (TcR excision circle) within these newly formed naïve $\mathrm{T}$ cells, identifying these cells as recent thymic emigrants.

After encountering and activation by their specific antigen, the naïve cells proliferate and become memory $\mathrm{T}$ cells. At this stage in their development, they have a decreased telomere length of their DNA strands and may become progressively differentiated and even senescent

Uremia-Associated Immunological Aging
[18]. Senescent T cells are characterized by lack of a proliferative response and expression of cell surface markers facilitating apoptosis. The number of recent thymic emigrants in the circulation, which can be assessed by TcR excision circle content, has an almost linear relationship with age in healthy individuals and as such can be used to establish the immunological age of the T cell system. This can be complemented by an analysis of the telomere length of memory $\mathrm{T}$ cells, which also shows a negative linear relationship with age and memory $\mathrm{T}$ cell differentiation status [7].

As judged by $\mathrm{T}$ cell telomere length and $\mathrm{TcR}$ excision circle content, an average difference of 20 years between the immunological age of ESRD patients and their calendar age exists [7]. The depletion of naïve T cells is related to a progressive decrease in glomerular filtration rate, but no major changes were found between predialysis ESRD patients or dialysis patients [18]. Also, the decrease in telomere length and memory $T$ cell differentiation status were very similar in patients with or without dialysis, which indicates that there is a bottom line in uremia-associated immunological aging [22]. Remarkably, other cells belonging to the lymphoid cell lineage, such as B cells, NK cells and lymphoid DC, are decreased in cell numbers both in aged healthy individuals and ESRD patients [8].

In contrast to cells belonging to the lymphoid cell lineage, the cells from the myeloid cell lineage do not decrease or even increase with age [21]. Again, the situation is very similar to what is observed in ESRD patients. Circulating numbers of monocytes are maintained or even increase with age, and there may be an increase in a proinflammatory subset of monocytes $\left(\mathrm{CD} 14^{+} \mathrm{CD} 16^{+}\right.$monocytes) [8]. This particular subset of monocytes has an increased potential for producing proinflammatory cytokines, has shorter telomeres and is associated with an increased risk for cardiovascular disease [12, 23].

\section{Role of Cytomegalovirus Infection in Immunological Aging}

Cytomegalovirus (CMV) infection has a profound influence on the circulating T cell population. CMV infection is acquired early in life and unlike other viral infections, on average $10 \%$ of the total circulating pool of $\mathrm{T}$ cells becomes CMV-antigen-specific (normally $<0.1 \%$ of $T$ cells are antigen specific for a given pathogen), an effect which remains during life. The CMV-antigen-specific memory $\mathrm{T}$ cells are predominantly highly differentiated and lack the costimulatory molecule CD28. The CD4 T 
Table 1. Changes in the cellular immune system observed both in uremia-associated immunodeficiency and physiological aging

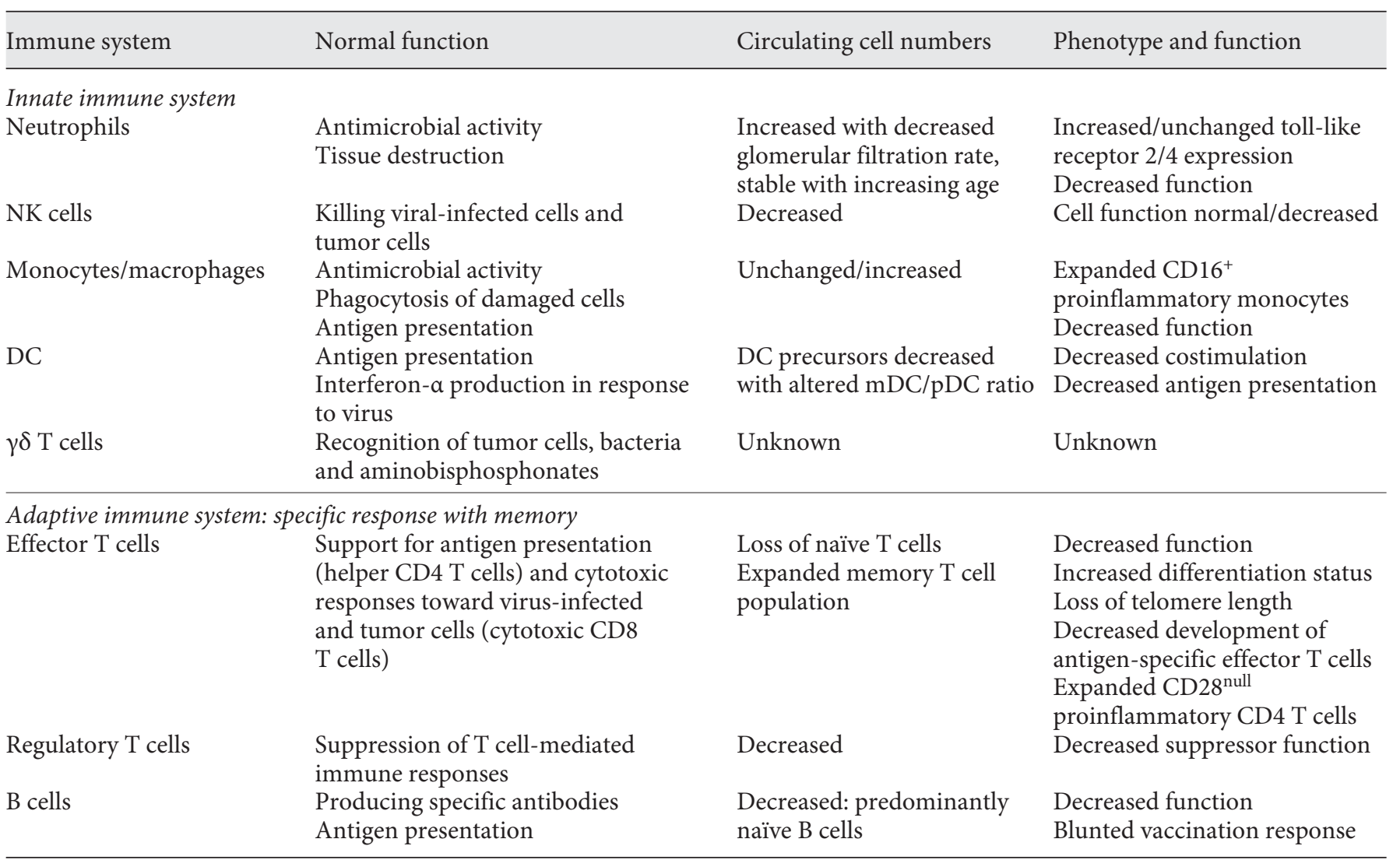

cells lacking CD28 (CD4 ${ }^{+} \mathrm{CD} 28^{\text {null }} \mathrm{T}$ cells) are an unusual population of cytotoxic $T$ cells, which have the potential to destabilize atherosclerotic plaques $[24,25]$. In ESRD patients, the effect of CMV infection on the composition of the circulating $\mathrm{T}$ cell pool is even greater, thereby increasing the differentiation status of CD4 and CD8 $\mathrm{T}$ cells and decreasing the average telomere length of CD8 memory T cells. This may be interpreted as an immunological aging effect but it is in fact limited to the memory $\mathrm{T}$ cell compartment and does not affect thymic output of T cells [26]. However, as in healthy individuals, the $\mathrm{CD} 4 \mathrm{CD} 28^{\text {null }} \mathrm{T}$ cells appear to be a nontraditional risk factor for cardiovascular disease [24].

\section{Immunological Aging in Relation to HSC and Epigenetic Modification}

The remarkable differential effect of increasing age on lymphoid and myeloid cell populations may be explained by the fact that HSC are skewed towards myeloid-gener- ating subsets at the expense of lymphoid-generating HSC subset in elderly individuals. This mechanism has been well documented in a mouse model and would explain the age-associated loss of naïve T cells, $\mathrm{B}$ cells and pDC [21]. This shift in HSC subsets may be caused by epigenetic changes acquired during lifetime. Uremia is associated with major epigenetic changes [27]. Therefore, one may hypothesize that loss of renal function leads to a premature skewing of lymphoid/myeloid HSC subsets. Of interest in this respect is the observation that expression of the KLOTHO gene is downregulated in ESRD patients because of methylation of the promoter region initiated by oxidative stress [28]. KLOTHO knockout mice have a typical premature aged phenotype, hence the term antiaging gene. This sequence of events may be the general principle which underlies the changes associated with aging of the immune system. Chronic inflammation and increased oxidative stress accelerate the induction of epigenetic changes, which normally arise late in life. 
Fig. 1. Uremia has a differential effect on cells from the lymphoid and myeloid cell lineage. Cells belonging to the lymphoid cell lineage, e.g. B cells, NK cells, pDC and effector or regulatory $\mathrm{T}$ cells, are all diminished in number and function. This may be caused by the combination of a proinflammatory milieu with increased oxidative stress. Activated effector T cells and diminished regulatory $\mathrm{T}$ cell function may foster systemic inflammation. Cells belonging to the myeloid cell lineage, e.g. granulocytes, monocytes, $\mathrm{mDC}$ or monocyte-derived DC, are present in similar or increased numbers and contribute to both the proinflammatory milieu and the increased oxidative stress. Circulating proinflammatory cell populations are expanded in both the lymphoid and myeloid cell lineage (CD4CD28 $8^{\text {null }} \mathrm{T}$ cells) and myeloid cell lineage (CD16 ${ }^{+}$monocytes).

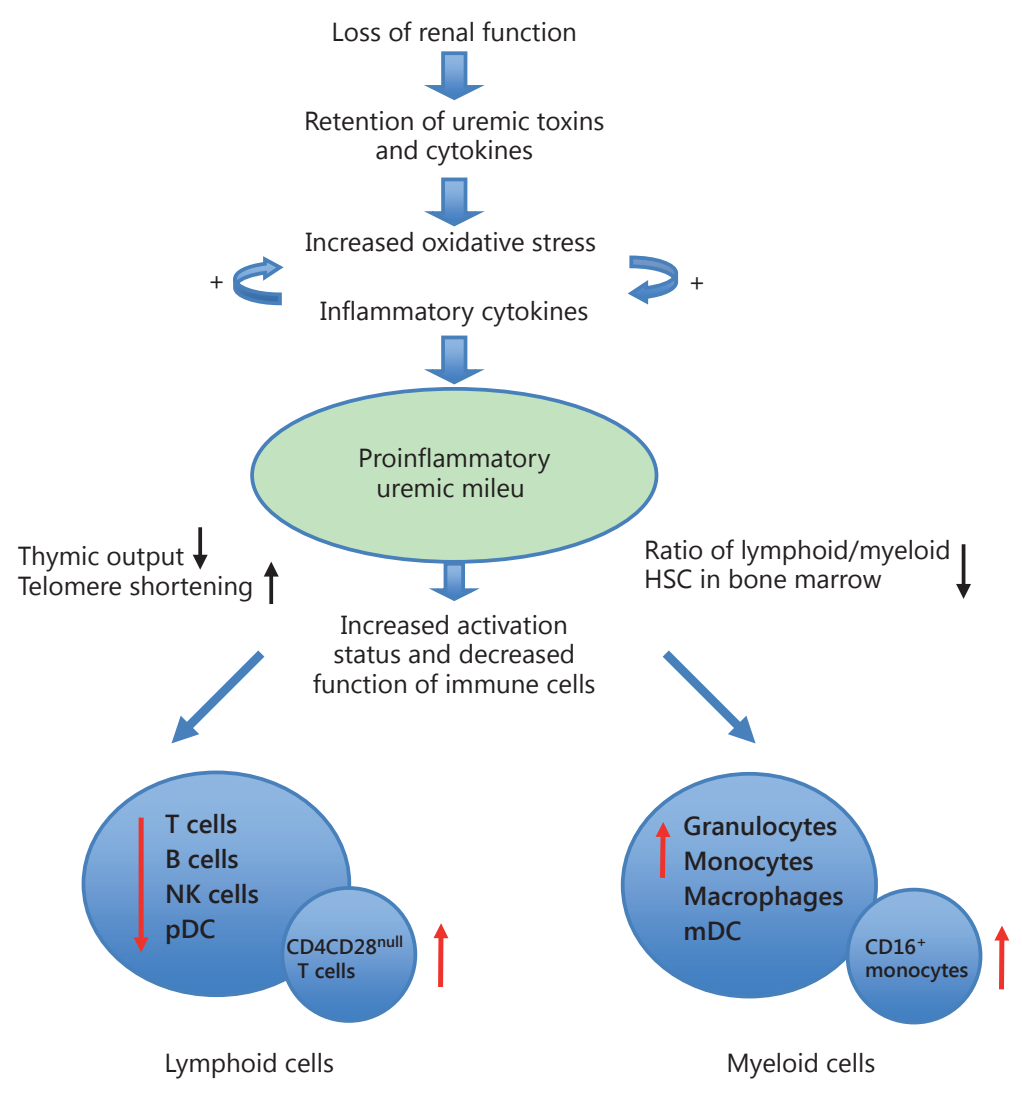

\section{Therapeutic Options to Reverse Premature Immunological Aging}

If chronic inflammation drives the ESRD-related immunological aging one would expect that adequate renal replacement therapy is mandatory to prevent further deterioration or reverse the changes observed. However, as noted above, we did not find major differences between ESRD patients with or without dialysis such as hemodialysis or peritoneal dialysis [22].

Interleukin-7 is a key cytokine for $\mathrm{T}$ cell homeostasis and as such may reverse ESRD-related lymphopenia. The first studies have shown a promising effect of interleukin-7 administration in humans with expansion of both naïve and memory $\mathrm{T}$ cells without significant side effects [29].

In addition, targeting the transcription factor $\mathrm{Nrf} 2$ may ameliorate oxidative stress and inflammation in ESRD patients. As these mechanisms are believed to be fundamental mechanisms in the chronic inflammatory condition of ESRD patients, the treatment with bardoxolone methyl, for example, may favorably attenuate immunological aging [30]. However, if immunological aging is directly related to uremia or inflammation, one would expect a reversal of $\mathrm{T}$ and $\mathrm{B}$ cell lymphopenia, less CD4CD28 $8^{\text {null }} \mathrm{T}$ cells and a decline in $\mathrm{CD} 16^{+}$monocytes after kidney transplantation. However, no impact of kidney transplantation on these cell populations was observed, while proinflammatory parameters rapidly decrease $[8,25,31]$. Although one cannot fully exclude the influence of immunosuppressive medication and only partly restored renal function, these observations indicate that immunological aging is not simply reversible. This may contribute to the reality that cardiovascular events, infections and malignancies remain life-threatening conditions for the kidney transplant patient. 


\section{Conclusion}

Progressive loss of renal function is associated with functional defects in virtually all cell populations of both the innate and adaptive immune systems, but the lymphoid cell lineage is more severely affected than the my- eloid cell lineage. The ESRD-related changes in the immune system resemble immunological aging in the (very) old healthy individuals, a concept known as premature immunological aging. Chronic inflammation/oxidative stress leading to epigenetic modification at the HSC level may be the underlying mechanism.

\section{References}

1 Verkade MA, van de Wetering J, Klepper M, Vaessen LM, Weimar W, Betjes MG: Peripheral blood dendritic cells and GM-CSF as an adjuvant for hepatitis $B$ vaccination in hemodialysis patients. Kidney Int 2004;66:614-621.

2 Stewart JH, Vajdic CM, van Leeuwen MT, Amin J, Webster AC, Chapman JR, McDonald SP, Grulich AE, McCredie MR: The pattern of excess cancer in dialysis and transplantation. Nephrol Dial Transplant 2009;24: 3225-3231.

-3 Vaziri ND: Oxidative stress in uremia: nature, mechanisms, and potential consequences. Semin Nephrol 2004;24:469-473.

-4 Anders HJ, Andersen K, Stecher B: The intestinal microbiota, a leaky gut, and abnormal immunity in kidney disease. Kidney Int 2013 83:1010-1016.

5 Akar H, Akar GC, Carrero JJ, Stenvinkel P, Lindholm B: Systemic consequences of poor oral health in chronic kidney disease patients. Clin J Am Soc Nephrol 2011;6:218-226.

6 Meier P, Golshayan D, Blanc E, Pascual M, Burnier M: Oxidized LDL modulates apoptosis of regulatory $\mathrm{T}$ cells in patients with ESRD J Am Soc Nephrol 2009;20:1368-1384.

7 Betjes MG, Langerak AW, van der Spek A, de Wit EA, Litjens NH: Premature aging of circulating $\mathrm{T}$ cells in patients with end-stage renal disease. Kidney Int 2011;80:208-217.

8 Betjes MG: Immune cell dysfunction and inflammation in end-stage renal disease. Nat Rev Nephrol 2013;9:255-265.

$\checkmark 9$ Betjes MG, Tuk CW, Visser CE, Zemel D, Krediet RT, Arisz L, Beelen RH: Analysis of the peritoneal cellular immune system during CAPD shortly before a clinical peritonitis. Nephrol Dial Transplant 1994;9:684-692.

- 10 Betjes MG, Visser CE, Zemel D, Tuk CW, Struijk DG, Krediet RT, Arisz L, Beelen RH: Intraperitoneal interleukin-8 and neutrophil influx in the initial phase of a CAPD peritonitis. Perit Dial Int 1996;16:385-392.

- 11 Sela S, Shurtz-Swirski R, Cohen-Mazor M, Mazor R, Chezar J, Shapiro G, Hassan K, Shkolnik G, Geron R, Kristal B: Primed peripheral polymorphonuclear leukocyte: a culprit underlying chronic low-grade inflammation and systemic oxidative stress in chronic kidney disease. J Am Soc Nephrol 2005;16 2431-2438.

12 Heine GH, Ulrich C, Seibert E, Seiler S, Marell J, Reichart B, Krause M, Schlitt A, Kohler H, Girndt M: CD14(++)CD16+ monocytes but not total monocyte numbers predict cardiovascular events in dialysis patients. Kidney Int 2008;73:622-629.

13 Peraldi MN, Berrou J, Dulphy N, Seidowsky A, Haas P, Boissel N, Metivier F, Randoux C, Kossari N, Guerin A, Geffroy S, Delavaud G, Marin-Esteban V, Glotz D, Charron D, Toubert A: Oxidative stress mediates a reduced expression of the activating receptor NKG2D in NK cells from end-stage renal disease patients. J Immunol 2009;182:16961705.

14 Vacher-Coponat H, Brunet C, Lyonnet L, Bonnet E, Loundou A, Sampol J, Moal V, Dussol B, Brunet P, Berland Y, Dignat-George F, Paul P: Natural killer cell alterations correlate with loss of renal function and dialysis duration in uraemic patients. Nephrol Dial Transplant 2008;23:1406-1414.

15 Lim WH, Kireta S, Thomson AW, Russ GR, Coates PT: Renal transplantation reverses functional deficiencies in circulating dendritic cell subsets in chronic renal failure patients. Transplantation 2006;81:160-168.

16 Hesselink DA, Betjes MG, Verkade MA, Athanassopoulos P, Baan CC, Weimar W: The effects of chronic kidney disease and renal replacement therapy on circulating dendritic cells. Nephrol Dial Transplant 2005;20: 1868-1873.

17 Agrawal S, Gollapudi P, Elahimehr R, Pahl MV, Vaziri ND: Effects of end-stage renal disease and haemodialysis on dendritic cell subsets and basal and LPS-stimulated cytokine production. Nephrol Dial Transplant 2010; 25:737-746.

18 Litjens NH, van Druningen CJ, Betjes MG: Progressive loss of renal function is associated with activation and depletion of naive T lymphocytes. Clin Immunol 2006;118:83-91.

19 Litjens NH, Huisman M, van den Dorpel M, Betjes MG: Impaired immune responses and antigen-specific memory CD4+ T cells in hemodialysis patients. J Am Soc Nephrol 2008; 19:1483-1490.

20 Pahl MV, Gollapudi S, Sepassi L, Gollapudi P, Elahimehr R, Vaziri ND: Effect of end-stage renal disease on B-lymphocyte subpopulations, IL-7, BAFF and BAFF receptor expression. Nephrol Dial Transplant 2010;25:205212.

21 McKay D, Jameson J: Kidney transplantation and the ageing immune system. Nat Rev Nephrol 2012;8:700-708.
22 Meijers RW, Litjens NH, de Wit EA, Langerak AW, van der Spek A, Baan CC, Weimar W, Betjes MG: Uremia causes premature ageing of the $\mathrm{T}$ cell compartment in end-stage renal disease patients. Immun Ageing 2012;9:19.

23 Merino A, Buendia P, Martin-Malo A, Aljama P, Ramirez R, Carracedo J: Senescent CD14+CD16+ monocytes exhibit proinflammatory and proatherosclerotic activity. J Immunol 2011;186:1809-1815.

-24 Betjes MG, Meijers RW, de Wit LE, Litjens $\mathrm{NH}$ : A killer on the road: circulating CD4(+) CD28null T cells as cardiovascular risk factor in ESRD patients. J Nephrol 2012;25:183-191.

25 Betjes MG, Huisman M, Weimar W, Litjens $\mathrm{NH}$ : Expansion of cytolytic CD4+CD28- T cells in end-stage renal disease. Kidney Int 2008;74:760-767.

26 Meijers RW, Litjens NH, de Wit EA, Langerak AW, van der Spek A, Baan CC, Weimar W, Betjes MG: Cytomegalovirus contributes partly to uremia-associated premature immunological ageing of the T-cell compartment. Clin Exp Immunol 2013, E-pub ahead of print.

27 Zawada AM, Rogacev KS, Hummel B, Grun OS, Friedrich A, Rotter B, Winter P, Geisel J, Fliser D, Heine GH: SuperTAG methylationspecific digital karyotyping reveals uremiainduced epigenetic dysregulation of atherosclerosis-related genes. Circ Cardiovasc Genet 2012;5:611-620.

28 Young GH, Wu VC: KLOTHO methylation is linked to uremic toxins and chronic kidney disease. Kidney Int 2012;81:611-612.

29 Sportes C, Hakim FT, Memon SA, Zhang H, Chua KS, Brown MR, Fleisher TA, Krumlauf MC, Babb RR, Chow CK, Fry TJ, Engels J, Buffet R, Morre M, Amato RJ, Venzon DJ, Korngold R, Pecora A, Gress RE, Mackall CL: Administration of rhIL-7 in humans increases in vivo TCR repertoire diversity by preferential expansion of naive T cell subsets. J Exp Med 2008;205:1701-1714

-30 Ruiz S, Pergola PE, Zager RA, Vaziri ND: Targeting the transcription factor Nrf2 to ameliorate oxidative stress and inflammation in chronic kidney disease. Kidney Int 2013;83: 1029-1041.

31 Scherberich JE, Nockher WA: CD14++ monocytes, CD14+/CD16+ subset and soluble CD14 as biological markers of inflammatory systemic diseases and monitoring immunosuppressive therapy. Clin Chem Lab Med 1999;37:209-213. 